\title{
A atividade de revisão linguística em Educação a Distância: uma análise dialógica
}

\author{
The linguistic review activity in Distance Education: a dialogical analysis
}

\author{
Vanessa Fonseca BARBOSA* \\ Universidade Federal do Pampa (UNIPAMPA) \\ Adail SOBRAL ${ }^{* *}$ \\ Universidade Católica de Pelotas (UCPel)
}

\begin{abstract}
RESUMO: Este artigo apresenta uma reflexão sobre uma pesquisa de mestrado acerca da atividade de Revisão Linguística desenvolvida no contexto da Educação a Distância (EaD) em uma instituição federal de ensino superior. O estudo ancorou-se nos postulados bakhtinianos, nas contribuições da Ergologia e da Clínica da Atividade, bem como nos estudos de Soares (2009), Oliveira (2010) e Sobral (2009) para demonstrar facetas da atividade pesquisada. Assim, comprovou-se que o trabalho investigado ocorre no âmbito de uma extensa rede de inter-relações, diretas e indiretas, entre diversos interlocutores (professores, alunos, revisores, etc.), sendo esse trabalho conjunto e cooperativo, mesmo quando há conflitos e divergências. Isso constitui o requisito mínimo para um resultado final satisfatório: a disponibilização de textos que são elaborados colaborativamente, através de um processo constante de interação e diálogo entre professores e revisores, a fim de proporcionar aos alunos de $\mathrm{EaD}$ um material didático mais adequado a suas necessidades.
\end{abstract}

PALAVRAS-CHAVE: Revisão linguística. Educação a Distância. Dialogismo.

ABSTRACT: We present a reflection on a Master's degree research about the activity of Linguistic Revision developed by a Nucleus of Revision in the context of Distance Learning (DL) in a Brazilian university. The study was anchored mainly in Bakhtinian postulates, in Ergology and Clinic of Activity, as well as in studies of Soares (2009), Oliveira (2010) and Sobral (2009) to demonstrate facets of the activity studied. Thus, it was found that the investigated work occurs within an extensive network of inter-relations, direct and indirect, between various interlocutors (teachers, pupils, reviewers, etc.), a collaborative and cooperative work even as there are conflicts and divergences. That constitutes the minimum indispensable conditions for a satisfactory final result: the production of Distance Learning texts prepared jointly by means of a constant process of interaction and dialogue among teachers and reviewers, in order to provide DL pupils a didactic material more appropriate to their necessities.

KEY WORDS: Linguistic revision. Distance learning. Dialogism.

\footnotetext{
* Mestrado em Linguística Aplicada; professora substituta da Universidade Federal do Pampa (UNIPAMPA) - campus Jaguarão, Curso de Graduação em Letras, e professora do Curso de Especialização a Distância "Mídias na Educação”, Universidade Federal de Pelotas (UFPel)/ Pelotas - RS - Brasil. E-mail: vanessaucpel@gmail.com.

** Doutorado em Linguística Aplicada e Estudos da Linguagem; é professor Adjunto II da Universidade Católica de Pelotas (UCPel), Programa de Pós-Graduação em Letras / Linguística Aplicada. Pelotas - RS Brasil. E-mail: adail.sobral@gmail.com.
} 


\section{Introdução}

A atividade de revisão de textos ultimamente vem ganhando um novo espaço: o da Educação a Distância (EaD). Em algumas Instituições de Ensino Superior (IES) que oferecem cursos na modalidade a distância, o material didático produzido para os fins de EaD passa pelo processo de revisão de textos. Este é o caso, por exemplo, da Universidade Federal do Rio Grande - FURG, a qual, através da sua Secretaria de Educação a Distância $(\mathrm{SEaD})$, dispõe de uma equipe multidisciplinar para auxiliar os professores quanto à elaboração de cursos e/ou disciplinas que serão ministrados por meio do ensino a distância. Dentre os vários profissionais que compõem a referida equipe multidisciplinar, há um grupo de revisores, os quais são responsáveis por realizar a revisão nos textos produzidos pelos docentes que atuam na SEaD. Produções textuais estas construídas para fins didáticos, visando à formação profissional do aluno a distância da FURG. Desse modo, a $\mathrm{EaD}$, sobretudo na FURG, tem proporcionado ao profissional de revisão estender o seu trabalho a um novo e amplo público, o que possibilita tornar desejável o conhecimento de como se desenvolve (ou pode se desenvolver) uma atividade, sob nosso ponto de vista, bastante cooperativa e enriquecedora. Atividade esta que, muitas vezes, por sua não institucionalização ${ }^{1}$ explícita ou por seu desconhecimento pelos usuários em geral, acaba silenciosa e escondida.

Este texto apresenta uma reflexão a partir da pesquisa de mestrado intitulada Uma análise dialógica da atividade de revisão linguística em $E a D^{2}$, a qual teve por objeto de estudo o desenvolvimento da atividade de revisão no contexto da EaD, com ênfase na atividade de revisão linguística desenvolvida pelo Núcleo de Revisão Linguística da SEaD/FURG. Deve-se destacar ainda que a pesquisadora, no período de realização do trabalho aqui exposto, fazia parte do Núcleo investigado e obteve o consentimento da Instituição investigada e dos participantes da pesquisa.

O principal objetivo da pesquisa consistiu em analisar facetas da atividade de Revisão Linguística no contexto da SEaD da FURG a fim de mostrá-la como prática social e discursiva, bem como de expor suas características laborais e enunciativas, tendo como objetivo último defender a proposta de vê-la como um agir colaborativo de construção de discursos. Para tanto, os materiais de análise do referido estudo consistiram em: seleções de atos enunciativos emergentes da interlocução entre alguns dos professores autores de materiais didáticos para a EaD na FURG e os profissionais do Núcleo de Revisão Linguística, que atuaram na SEaD durante o ano de 2010; da exposição de dois exemplos do trabalho de revisão realizado em dois desses materiais; e, por fim, da aplicação de um questionário a dois revisores com vistas a lhes proporcionar um espaço de reflexão sobre o trabalho realizado.

A investigação ancorou-se nos pressupostos bakhtinianos de língua/linguagem e em postulados sobre o trabalho, advindos da Ergologia e da Clínica da Atividade (CLOT e FAÏTA, 2000), bem como nos estudos de Oliveira (2010) e Soares (2009), a respeito das atividades de revisão e produção textual, e de Sobral (2008) acerca do trabalho de tradução como um trabalho com discursos. Na sequência, discorreremos brevemente sobre nossa filiação teórica; apresentaremos nosso contexto de pesquisa, a fim de que se compreenda o espaço em que se insere o revisor na EaD da FURG; e os princípios metodológicos que

\footnotetext{
${ }^{1}$ Dizemos “não-institucionalização" porque o revisor que atua na modalidade a distância não ocupa um cargo público, através de contratação via concurso, mas sim recebe uma bolsa de apoio financeiro mensal pelo Fundo Nacional de Desenvolvimento da Educação (FNDE).

${ }_{2}^{2}$ Pesquisa desenvolvida por Vanessa Fonseca Barbosa, no PPPGL - UCPel, sob a orientação do Prof. Dr. Adail Sobral, e defendida em fevereiro de 2012.
} 
nortearam a investigação científica ora apresentada. Por fim, mostraremos trechos de uma das análises realizadas em nosso estudo, através dos quais é possível verificar os diálogos estabelecidos entre um professor da SEaD e o Núcleo de Revisão Linguística, dos quais advêm dizeres e compreensões distintas sobre a atividade realizada.

Através da pesquisa, conseguimos verificar que a atividade de revisão constitui de fato uma prática social e discursiva, um agir colaborativo de construção de discursos voltados para promover a formação do usuário final, no caso o aluno de EaD na FURG. O trabalho realizado pelo Núcleo ocorre no âmbito de uma extensa rede de inter-relações, diretas e indiretas, entre diversos interlocutores (professores, tutores, alunos, revisores, etc.), sendo esse trabalho conjunto e cooperativo, mesmo quando há conflitos e divergências, que são, afinal, constitutivos de todo diálogo.

\section{Dialogismo, Ergologia e Clínica da Atividade: alguns elementos}

A teoria bakhtiniana constituiu a principal base do nosso trabalho porque possibilitou apreender as relações interlocutivas estabelecidas entre os profissionais pesquisados e os acentos de valor que eles atribuem à atividade de revisão. Uma análise dialógica dessa atividade se impôs também devido à especificidade da posição do revisor no que se poderia chamar de rede interlocutiva da preparação de material para a EaD. Na visão do chamado Círculo de Bakhtin, que na realidade não existiu como tal, língua/linguagem é concebida como um fenômeno intrinsecamente social e heterogêneo, construído a partir das interações entre os diversos interlocutores (BAKHTIN; VOLOCHÍNOV, 2010). Na perspectiva bakhtiniana, admitir a natureza social da linguagem significa refletir a respeito desta a partir de situações reais, nas quais há a permanente troca de dizeres e construção de sentidos entre os múltiplos indivíduos que formam a sociedade.

Os integrantes do Círculo desenvolveram um olhar dialógico de língua/linguagem, cujo foco são as situações concretas de interação verbal. A linguagem é definida como

\footnotetext{
Um sistema semiótico aberto que se sustenta numa dialética entre um plano convencional dotado de certa estabilidade [...], um componente que tende à permanência, e um plano marcado pela instabilidade [...]. A linguagem é, por conseguinte, fruto de uma tensão dialética contínua entre estabilidade e instabilidade, entre a cristalização de significações e a amplitude dos temas sociais e historicamente possíveis. A compreensão da linguagem nesses termos tem como centro a inter-ação linguística, uma inter-ação entre sujeitos concretos, ação em que sempre se fazem presentes diferentes formas de apropriação do mundo (SOBRAL, 2009, p. 89).
}

Para o Círculo, se "uma forma linguística for tomada exclusivamente enquanto um sinal e for assim compreendida pelo receptor, ela não terá para ele nenhum valor linguístico" (BAKHTIN; VOLOCHÍNOV, 2010, p. 97). Tal convicção subjaz o trabalho do Núcleo de Revisão Linguística da SEaD/FURG, já que este sempre considera o texto em relação ao contexto em que ele está inserido, levando também em conta os interlocutores a quem se destina e as finalidades de sua produção.

Esses posicionamentos põem em destaque o princípio segundo o qual a natureza da linguagem reside na ação entre indivíduos e expõem a importância dos pressupostos bakhtinianos para a concretização da pesquisa apresentada. Isto porque, debruçar-se apenas sobre o estudo das unidades linguísticas não seria suficiente para abarcar esses aspectos fundamentais da linguagem destacados pelo Círculo, tampouco daria conta de explicar o trabalho realizado pelo Núcleo de Revisão da SEaD/FURG, já que a essência da 
decodificação "não consiste em reconhecer a forma utilizada, mas em compreendê-la num contexto concreto preciso, compreender sua significação numa enunciação particular. Em suma, trata-se de perceber seu caráter de novidade e não somente sua conformidade à norma” (BAKHTIN; VOLOCHÍNOV, 2010, p. 96).

Recorremos também aos pressupostos da Ergologia e a textos basilares da Clínica da Atividade (CLOT; FAÏTA, 2000) para melhor compreender os trabalhadores do Núcleo de Revisão Linguística e a forma como estes apreendem e lidam com a linguagem como trabalho (NOROUDINE, 2002). A Ergologia tem como sua propedêutica a Ergonomia da atividade, surgida na França, em meados dos anos 40, que tinha como preocupação central o questionamento à visão mecanicista do trabalho, embasada em uma proposta inédita do norte-americano Frederick Winslow Taylor (2011), para a qual importava garantir que a execução e o resultado final de qualquer tarefa fossem bem-sucedidos, sem que se levasse em conta nenhum fator relacionado ao executor desta: o ser humano. A Ergonomia da atividade teve como foco de investigação a relação entre a atividade prescrita e a realizada, considerando a subjetividade na concretização do trabalho. Essa ciência pode ser compreendida como "um conjunto de conhecimentos sobre o ser humano no trabalho e uma prática de ação que relaciona intimamente a compreensão do trabalho e sua transformação” (SILVA, 2004, p. 84).

A Ergologia nasceu na França, na década de 80, tem um foco pluridisciplinar e, embora tenha na Ergonomia da atividade um de seus aportes, ela vai além da constatação entre o prescrito e o real, e propõe a norma e a renormalização do trabalho a partir da consideração das vozes dos atores do trabalho. Schwartz (2007), um dos principais teóricos da Ergologia, afirma que toda a atividade de trabalho é perpassada por um debate permanente entre as normas antecedentes e as renormalizações (SCHWARTZ, 2007). As normas antecedentes, tal como supõe o nome, preexistem a toda atividade e abarcam desde as práticas diárias mais comuns - como o acerto de objetivos, horários, apresentação de programas tecnológicos, etc. - até as prescrições, enquanto as renormalizações comprovam o fato de que, quando o humano está em foco, é praticamente inviável lidar com uma ideia de trabalho e de trabalhador única e homogênea, pois o homem é sempre capaz de ressignificar sua prática, a partir da situação concreta em que atua, isto é, ele é capaz de renormalizá-la, ou seja, redefini-la em seus termos específicos. Isso também ocorre porque, embora as normas tenham de existir para assegurar um bom convívio em sociedade, temos a possibilidade de fazer escolhas, através das situações em que vivemos, o que, por sua vez, abre espaço para a criação de posturas singulares que nos auxiliam a encarar os desafios cotidianos.

A proposição da Clínica da Atividade partiu do pressuposto de que é deveras importante ao trabalhador se debruçar criticamente sobre a atividade que desempenha, a fim de melhor compreendê-la e realizá-la, o que pode ocorrer, inclusive, através da criação de conceitos por parte do trabalhador. Segundo o fundador da referida clínica, o objetivo desta é "compreender [a atividade] para transformar, e isto em resposta a demanda dos próprios interessados” (CLOT, 2001, p. 1), quais sejam: os atores do trabalho. Dessa maneira, o trabalho é concebido como "uma base que mantém o sujeito no homem, visto que é a atividade mais transpessoal possível” (CLOT, 2006, p. 8). O autor afirma ainda que o que se busca, com a Clínica, é compreender a atividade para além de uma concepção amorfa de trabalho, a fim de poder abarcar também os conflitos existentes nas situações reais em que ele se desenvolve (CLOT, 2001). Nesta concepção, 
A atividade não é somente aquilo que se faz. O real da atividade é também o que não se faz, aquilo que não se pode fazer, o que se tenta fazer sem conseguir - os fracassos - aquilo que se desejaria ou poderia fazer, aquilo que não se faz mais, aquilo que se pensa ou sonha poder fazer em outro momento [...]. A atividade possui então um volume que transborda a atividade realizada (CLOT, 2006, p. $6)$.

Portanto, para analisar a atividade de trabalho é preciso "encontrar o real sob o realizado, isto é, as escolhas, as decisões que precedem a tarefa, o que poderia ter sido feito de outro modo, mas não o foi; os acordos estabelecidos entre os interlocutores reais ou potenciais” (CLOT et al., 2001, p. 18). Para observar e analisar os ambientes múltiplos e complexos nos quais as atividades e relações de trabalho se dão, as pesquisas embasadas no referencial da Clínica da Atividade demonstram a relevância de se proporcionarem espaços nos quais os trabalhadores possam falar sobre a atividade que realizam. Ademais, procura-se também propiciar aos trabalhadores a oportunidade de se observarem em momentos de atuação profissional para que possam falar sobre como se veem, já que "a verbalização é em si mesma uma legítima atividade do sujeito, e não apenas um meio de acesso a outra atividade” (CLOT, 2006, p. 135). Em nossa pesquisa, não utilizamos literalmente os métodos desenvolvidos pela Clínica da Atividade, mas fizemos uma adaptação destes, em decorrência da natureza dos dados, conforme explicaremos na seção que trata da metodologia.

Valemo-nos ainda de trabalhos de Soares (2009), Oliveira (2010) e Sobral (2008) para tratar, de diferentes perspectivas, o trabalho com textos de autoria de outros sujeitos. Soares (2009) aborda a produção e avaliação de textos escolares, especialmente com relação à importância dada para a construção de feedbacks ${ }^{3}$ aos autores de textos por parte de professores de produção textual, algo que se aproxima da atividade de revisão. Oliveira (2010), por sua vez, tem por foco o trabalho de revisão textual de uma perspectiva bakhtiniana. Segundo a autora, a concepção tradicional de revisão

[...] é pautada no senso comum de que revisar resume-se a corrigir ortografia, pontuação, concordância verbal e nominal, de acordo com as normas apontadas em gramáticas, dicionários e manuais, sendo a revisão tratada como uma das etapas de reescritura em que se focalizam os aspectos estruturais do texto (OLIVEIRA, 2010, p. 17).

Em contraposição a isso, a autora entende a revisão como atividade recursiva e, como tal, pode ocorrer em qualquer etapa do processo de escrita, o que supera uma concepção linear da atividade. Oliveira (2010) demonstra que a atividade de revisão textual comumente é relacionada com situações de sala de aula e justamente por isso as pesquisas concretizadas praticamente não tratam da interação revisor-autor-texto. Assim, nos raros casos em que o trabalho do revisor está em foco, a tendência é abordá-lo como uma "tarefa voltada meramente para a resolução de problemas de ordem estrutural e notacional de perspectiva cognitivista, não levando em conta os aspectos discursivos que cercam as metas volitivas do autor" (OLIVEIRA, 2010, p. 24).

Justamente sobre esses aspectos discursivos é que focamos nosso trabalho com a intenção de demonstrar quais os discursos que permeiam o trabalho do revisor, sobretudo em um contexto multifacetado, tal como o é o da EaD. Para tanto, recorremos a Sobral

\footnotetext{
${ }^{3}$ A expressão feedback é entendida aqui de acordo com Soares (2009), para quem a expressão no idioma inglês designa um conjunto de intervenções do professor no texto do aluno, as quais forneçam "informações que capacitem o aprendiz a identificar os aspectos de seu desempenho que são aceitáveis e passíveis de melhoria por algum meio específico” (SOARES, 2009, p. 51).
} 
(2008), pois o autor trata do trabalho do tradutor sob um ponto de vista enunciativo da linguagem. Tomar a atividade de tradução dessa perspectiva, fundada nas propostas bakhtinianas, permite-nos vislumbrar a proximidade daquela com a atividade de revisão, pois ambas se encontram em um entre-lugar e têm por objeto o discurso, cuja materialidade é, claro, um texto, mas não se esgota nele. Por isso, quanto mais claros estiverem os posicionamentos do revisor e do autor do texto sobre como compreendem e o que esperam da atividade de revisão, os desentendimentos e os equívocos entre eles tendem a ser menor e passam a ocorrer com pouca frequência, dando lugar a uma colaboração, já que, em muitos casos, revisar também pode significar "rediscursivizar, transpor e transcriar um discurso em outro discurso" (SOBRAL, 2008, p. 73), em vez de deter-se em aspectos textuais estritos.

\section{Contexto de pesquisa}

No dia 7/12/2007, diante do crescente envolvimento da Universidade Federal do Rio Grande - FURG em diferentes programas ${ }^{4}$ de Educação a Distância (EaD), foi criada, pelo Conselho Universitário (CONSUN) da FURG, através da Resolução $n^{\circ}$ 034/2007, a Secretaria de Educação a Distância (SEaD). Esta, desde então, tem por incumbência, dentre outras atribuições, a formação inicial e continuada de professores e tutores, bem como a gerência dos investimentos recebidos pelo governo federal para a organização estrutural e de pessoas ligadas à EaD nessa instituição de ensino superior.

Assim, no intuito de atender às suas demandas, a SEaD da FURG formou, já em seu primeiro ano de atuação (2007), uma equipe multidisciplinar para dar apoio administrativo, técnico e pedagógico tanto aos professores que atuassem na modalidade a distância quanto àqueles que atuassem apenas na presencial e que desejassem utilizar a plataforma digital (Moodle). Tal equipe multidisciplinar foi composta, desde sua primeira configuração, por profissionais diversos como, por exemplo, professores e acadêmicos dos cursos de graduação e pós-graduação de diferentes áreas do conhecimento para atuarem, principalmente, nas seguintes funções: revisão linguística, diagramação, criação de videoaula, web conferência, suporte técnico e apoio pedagógico. Atualmente, a equipe multidisciplinar da SEaD é composta por cerca de setenta bolsistas (acadêmicos de graduação, pós-graduação, professores e técnicos da instituição), os quais estão distribuídos em: uma Coordenação Geral, duas Assessorias (uma Pedagógica e a outra de Gestão), um Conselho ${ }^{5}$ e oito Núcleos, conforme a Figura 1:

\footnotetext{
${ }^{4}$ Disponível em: <http://www.sead.furg.br/index.php/sead/sobre\#>. Acesso em: 2 nov. de 2011. Ver também Novello (2011) Disponível em: <http://bdtd.furg.br/tde_busca/arquivo.php?codArquivo=466>. Acesso em 5 nov de 2011.

${ }^{5}$ O Conselho da SEaD é composto por um membro de cada um dos Núcleos e tem função consultiva, não deliberativa.
} 


\section{Figura 1 - Estrutura atual da SEaD/FURG}

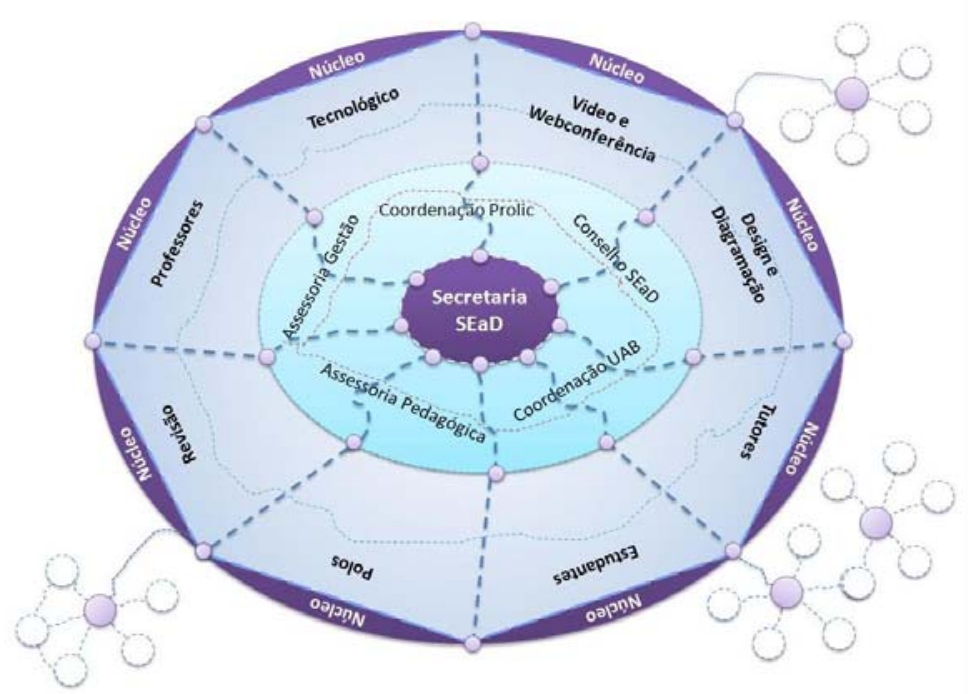

(Fonte: SEaD/FURG)

O Núcleo de Revisão Linguística da SEaD tem por finalidade essencial concretizar a função prevista no anexo I da resolução número vinte e seis ${ }^{6}$ do Fundo Nacional de Desenvolvimento da Educação (FNDE): "realizar a revisão de linguagem do material didático desenvolvido para a modalidade a distância”. Assim, toda a disciplina que acontece através da SEaD tem à disposição do docente responsável por organizá-la a atividade de trabalho desenvolvida pelo Núcleo de Revisão Linguística. Por isso, quando um professor assume o compromisso de ministrar uma disciplina em um dos cursos da modalidade de Educação a Distância na FURG, ele recebe o contato eletrônico do Núcleo de Revisão Linguística, o qual funciona como a "porta de entrada" de todo o material produzido para os cursos oferecidos pela SEaD/FURG.

Os professores são orientados a encaminhar seus materiais para o Núcleo de Revisão com, no mínimo, três meses de antecedência do início das suas disciplinas, a fim de garantir que o processo de produção de material possa ocorrer com o comprometimento habitual da SEaD, o qual, sob o ponto de vista desta, é fundamental para que se possa garantir um trabalho de qualidade ao aluno. Então, após a realização do atendimento com o Núcleo de Professores e o envio do material ao e-mail do Núcleo de Revisão Linguística, este faz as suas contribuições no texto, assim como as sugestões e adequações gramaticais necessárias, e, tão logo findado o seu trabalho, repassa os arquivos ao Núcleo de Design e Diagramação. Este, por sua vez, realiza as suas atividades e, após concluí-las, disponibiliza as versões finais das aulas na plataforma Moodle ou as reenvia ao professor para que ele mesmo as insira no ambiente virtual e organize o material de acordo com os tópicos de cada aula, os quais, nesse momento, já foram especificados pelo docente através do preenchimento do roteiro ${ }^{7}$.

O processo descrito está representado pela Figura 2:

\footnotetext{
${ }^{6}$ A resolução 26 do FNDE “Estabelece orientações e diretrizes para o pagamento de bolsas de estudo e de pesquisa a participantes da preparação e execução dos cursos dos programas de formação superior, inicial e continuada no âmbito do Sistema Universidade Aberta do Brasil (UAB), vinculado à Coordenação de Aperfeiçoamento de Pessoal de Nível Superior (Capes)” (BRASIL, 2009, p.1).

7 O Roteiro está disponível em: <http://www.uab.furg.br//file.php/1/guiadosprofessores/html/roteiro.html>. Acesso em: 5 de nov. de 2011.
} 


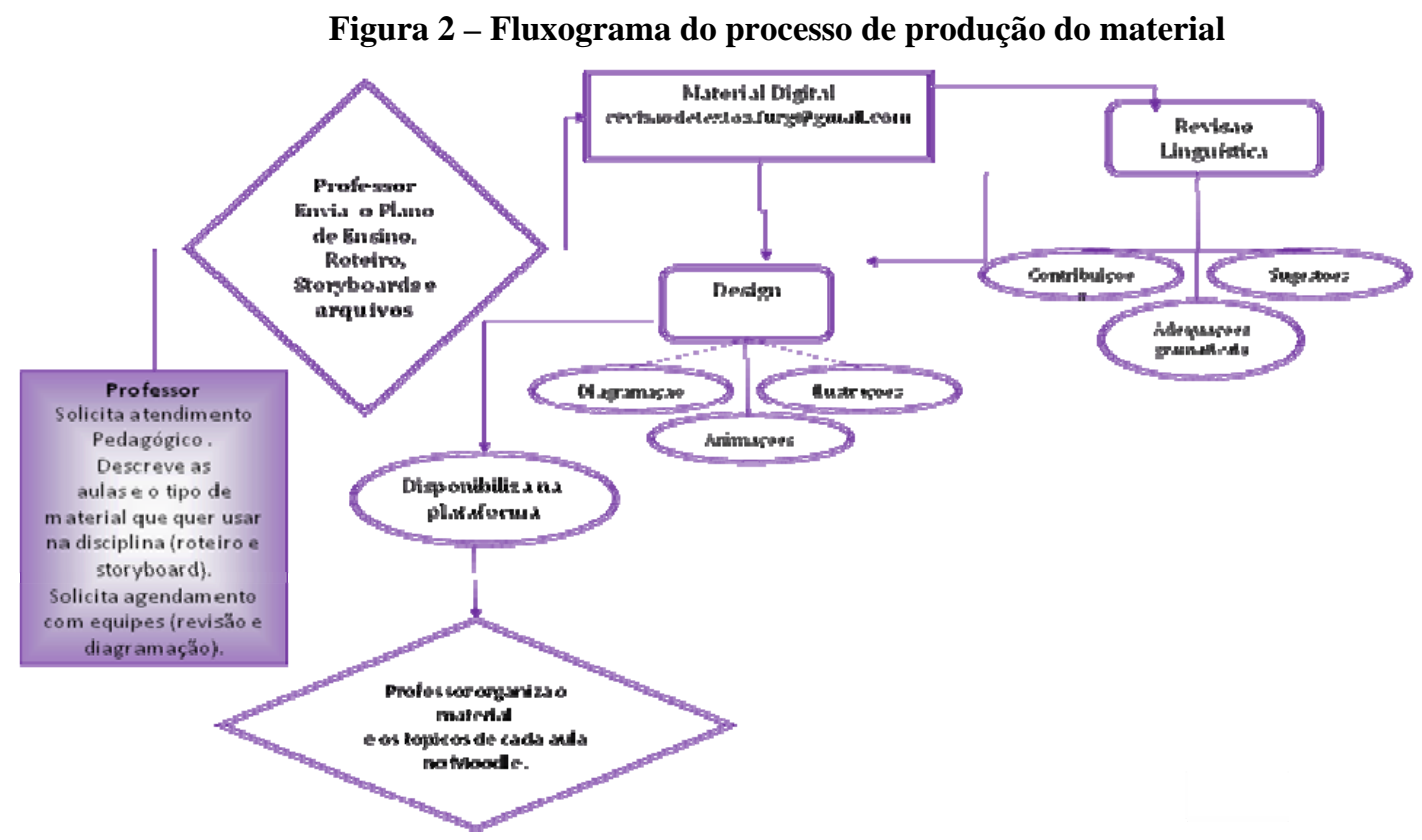

(Fonte: SEaD/FURG)

A passagem de uma etapa a outra não ocorre da forma linear suposta pela Figura 2. Quando um texto passa pela revisão do Núcleo, geralmente, o material retorna ao professor com a inserção de vários comentários ${ }^{8}$, principalmente de teor semântico, para que o professor possa apreciá-los e, posteriormente, dar um retorno à equipe de revisão. Ao falarmos em teor semântico referimo-nos, sobretudo, a observações que não têm dizem respeito a aspectos estritamente estruturais de um texto, mas sim dos que se relacionam à clareza e coerência da produção elaborada, a partir do que se supõe ser as necessidades presumidas do leitor final, o aluno de EaD. Nesse sentido, cabe destacar também que as adequações gramaticais (ver Figura 2) necessárias são realizadas diretamente pelo Núcleo, ou seja, antes de os arquivos retornarem aos docentes para sua apreciação, uma vez que é dispensável, na opinião do Núcleo, explicar cada regra gramatical considerada na revisão das produções textuais. A equipe de revisão dá destaque a um diálogo que possibilite a reflexão com os autores a respeito de questões discursivas, as quais direcionam o olhar a, por exemplo, confirmar se as propostas a que se propôs o texto na introdução são contempladas no decorrer da escrita ou a verificar a presença de incoerências, entre outros.

Destaca-se o fato de as contribuições (ver Figura 2) realizadas serem de cunho semântico, uma vez que têm por objetivo dialogar com o docente sobre a constituição geral do texto produzido, visando sempre à compreensão presumida do destinatário final, que é o aluno de EaD. Faz-se importante evidenciarmos ainda que a última palavra quanto à versão final do texto é sempre do autor deste, isto é, do professor. Disso decorre o fato de o Núcleo de Revisão Linguística da SEaD sempre realizar sugestões (ver Figura 2 ) no texto, assinalando-as ao docente, para que ele possa decidir o que deve ser feito. Assim, após o retorno do professor ao Núcleo, a equipe relê os textos e, caso não tenha mais nenhuma observação para inserir, repassa os arquivos para o Núcleo de Design e Diagramação. Este Núcleo, da mesma forma, também estuda o material e dialoga com os professores no decorrer do seu trabalho, a fim de que possam construir coletivamente e em um processo colaborativo as aulas que serão ministradas através dos cursos a distância da FURG.

\footnotetext{
${ }^{8}$ Estes comentários são inseridos através da ferramenta disponível no editor de texto Word.
} 


\section{Metodologia}

O principal recurso de comunicação entre o Núcleo de Revisão Linguística da $\mathrm{SEaD}$ e os docentes que produzem o material para a EaD/FURG é a troca de e-mails. Por esse motivo, enfatizamos alguns e-mails trocados como fonte de dados para a análise da atividade. Inicialmente, realizamos um levantamento de e-mails encaminhados pelos docentes ao endereço eletrônico do Núcleo de Revisão entre os meses de fevereiro a dezembro de 2010. A partir daí, separamos quatorze diálogos via e-mail, nos quais era mais claramente identificável um posicionamento dos professores quanto à atividade de revisão desenvolvida em seus textos. Após esse levantamento, pudemos verificar a existência de manifestações diversas a respeito da atividade realizada nos materiais produzidos pelos professores atuantes na SEaD. Evidentemente, nos referidos e-mails, por se tratar da exposição de diálogos trocados entre interlocutores diversos, ambos os profissionais (revisor e professor) têm suas vozes demonstradas. Ainda assim, nosso foco, com a seleção das correspondências eletrônicas, foi dado à posição enunciativa dos professores, uma vez que, através desta, pudemos observar as bases dos relacionamentos dos docentes com o Núcleo e, em consequência, uma das facetas da atividade pesquisada.

Nosso próximo passo foi examinar o teor geral dessas manifestações dos professores, o que nos permitiu verificar que os posicionamentos dos docentes realizavam certo número de atos enunciativos específicos que denominamos: discordância com a proposta feita, acolhimento das sugestões, agradecimento e ênfase na preocupação de tornar o material mais claro ao aluno. Em alguns casos, um mesmo e-mail apresentava mais de um ato enunciativo como, por exemplo, agradecimento/acolhimento. Esclarecemos também que, de todos os e-mails considerados, apenas dois deles exibiram os atos que denominamos discordância da proposta feita. A Figura 3 ilustra o levantamento realizado:

Figura 3 - Atos enunciativos dos docentes

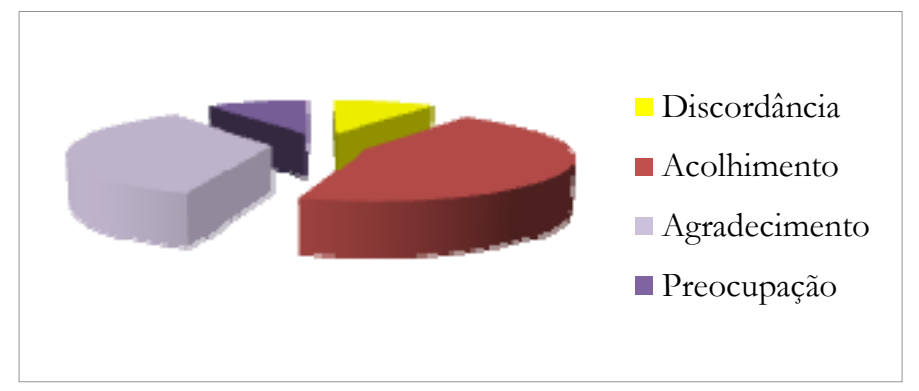

(Fonte: PESQUISA DO AUTOR)

Nossa próxima etapa consistiu em analisar por completo alguns desses diálogos virtuais entre o Núcleo e os docentes que na SEaD atuaram no ano de 2010, ao invés de somente trechos dessas interações, pois essa análise nos traria uma visão mais abrangente do processo. Para tanto, selecionamos dois dentre os quatorze diálogos trocados por $e$-mail entre a equipe de revisão da SEaD e os professores, bem como alguns trechos dos textos aos quais esses dois diálogos se referem para serem estudados na íntegra. Sendo assim, em nossa pesquisa, selecionamos um exemplo que revela atos discursivos de acolhimento de sugestões/agradecimento e o outro que se refere à discordância da proposta feita. Estes dois casos exemplares de tom oposto foram escolhidos porque atendem ao objetivo de mostrar distintas opiniões acerca da mesma atividade e de como deve ocorrer a relação entre revisores e professores ao ver desses profissionais, e não dos documentos prescritivos da SEaD. Tais exemplos concretos demonstram subsidiariamente de que modo a atividade 
realizada pelo Núcleo contribui para o processo de produção de material e, no presente artigo, traremos parte de um desses exemplos para a melhor compreensão da pesquisa realizada.

Mesmo com esse material, percebemos, em nossa pesquisa, que não poderíamos tratar da atividade somente através das correspondências eletrônicas, porque nos $e$-mails o que está no centro da relação entre os interlocutores é o desenvolvimento do trabalho em si, isto é, o foco da interação é a negociação, o diálogo com o autor do texto, não a reflexão sobre a atividade em si, ainda que ela perpasse as correspondências eletrônicas. Sendo assim, se analisássemos apenas os e-mails trocados não teríamos os subsídios necessários para que pudéssemos tentar compreender a atividade de revisão linguística desenvolvida pelo Núcleo da SEaD de modo mais holístico, tal como proposto pela Clínica da Atividade, compatível com os pressupostos das teorias do Círculo de Bakhtin na qual nos baseamos. Em vista disso, fomos levados a gerar outros dados a fim de complementar nosso corpus de análise: elaboramos um questionário, aplicado por e-mail a dois revisores atuantes no Núcleo, pretendendo dar a esses profissionais a oportunidade de refletir diretamente sobre a atividade que realizam, assim como expor quais posicionamentos a realização de uma mesma atividade pode provocar em diferentes trabalhadores de um mesmo grupo. Se, no caso dos professores, identificamos seu posicionamento diante das propostas do grupo de revisão; no caso dos revisores, nosso foco foi levá-los a descrever sua própria atividade a fim de podermos avaliar os critérios em que se baseiam seus posicionamentos enquanto trabalhadores.

Esse instrumento se compôs das seguintes questões:

- Como descreves a tua relação enquanto revisor da SEaD/FURG com os professores elaboradores de material didático para a EaD/FURG?

- Na apresentação do "Fluxograma da Produção de Material”, as atividades do revisor aparecem dividas em "contribuições”, “sugestões” e “adequações gramaticais". Sendo assim, pedimos que digas o que entendes que cada uma delas significa em teu trabalho, bem como que respondas se elas resumem toda a atividade realizada pelo Núcleo de Revisão Linguística da SEaD/FURG ou se há outras etapas ou ações na atividade. Em caso afirmativo a este último questionamento, quais seriam essas etapas?

- Como caracterizas o tutor e o aluno da EaD no desenvolvimento da tua atividade, uma vez que eles são os leitores, mediador e final, respectivamente, do material revisado pelo Núcleo em que atuas?

A primeira questão pretendeu identificar de que maneira o sujeito visualiza seu próprio trabalho em sua relação com o coletivo e com os demais atores diretos dessa atividade, os docentes. A segunda buscou verificar a diferença entre a atividade prescrita e a atividade realizada, a fim de chegar a uma descrição próxima do real da atividade. A terceira pretendeu identificar a que tipo de interlocutor presumido o profissional de revisão da EaD/FURG se dirige ao desenvolver a sua atividade, do ponto de vista da compreensão que pretende alcançar do leitor mediador (o tutor) e final (o aluno de $\mathrm{EaD}$ ). As questões do instrumento visam desvelar especificamente aspectos que a pesquisa mostrou ser relevantes; cada uma delas busca cobrir um dos aspectos constituintes da atividade do ponto de vista do profissional que a realiza. Assim, consideramos o posicionamento do sujeito revisor com respeito à atividade de trabalho e às renormalizações nas relações que ele estabelece com os produtores e leitores do material. Em outras palavras, buscamos ver a relação do revisor com o interlocutor docente e o modo como aquele vê essa relação do 
ponto de vista do processo de trabalho; a diferença entre prescrito e realizado; e a "imagem" ou "representação" que faz do leitor final, o aluno da EaD.

\section{Análise dos dados: um exemplo}

Nesta seção, apresentamos uma breve análise de partes do diálogo ${ }^{9}$ estabelecido entre o Núcleo e o "Professor A":

Segue o texto 1 da apostila [...] para revisão.

Professor A

Bom dia, [Professor A].

Confirmamos o recebimento.

Atenciosamente,

Equipe de Revisão Linguística

Os enunciados desta conversa revelam uma apresentação geral dos dois interlocutores no início do processo de produção de material de uma dada disciplina a partir do trabalho do Núcleo. O professor assina enquanto sujeito individual: "Professor A”, ao passo que o Núcleo não explicita o nome de um revisor específico, apresentando-se como coletivo de trabalho: "Equipe de Revisão Linguística".

O e-mail que deu continuidade a esse diálogo foi enviado pelo Núcleo:

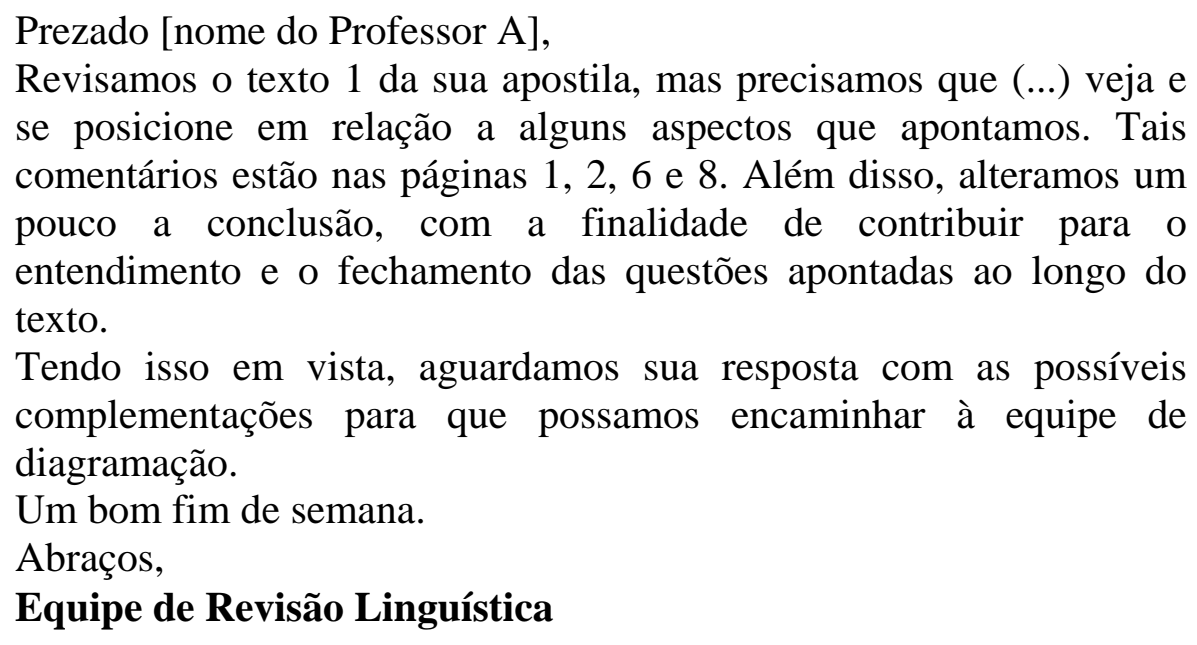

Este $e$-mail tem por objetivo tratar do desenvolvimento da atividade em si, e seus enunciados orientam o professor na releitura de seu texto, ao apontar as páginas dos comentários realizados, expondo as justificativas das alterações. Vê-se a sinalização do Núcleo para o fato de que a decisão pelo acolhimento (ou não) das sugestões está a cargo do professor: “... aguardamos sua resposta com as possíveis complementações para que possamos encaminhar à equipe de diagramação” (Núcleo de Revisão Linguística).

A seguir vem a réplica do Professor A:

\footnotetext{
9 Todas as interações aqui transcritas estão iguais às originais, sem que tenham passado por qualquer revisão e/ou alteração.
} 


\begin{abstract}
Segue o texto com as observações. Solicito que o texto não seja reescrito como foi feito no ultimo parágrafo, pois nem sempre o que vocÊs colocam é a intenção de quem escreveu até porque o campo teórico provavelmente é diferente! Isso já conversado [uma autoridade do Núcleo] pois com boa intenção pode-se alterar o sentido do texto. Não quero que vocês me levem a mal, mas a revisao é da parte linguistica e vocÊs podem e devem fazer sugestão como colocaram no item 1 , mas não podem reescrever o texto, podem reescrever como sugestão.

Peço que depois da revisao final o texto não seja enviado para a draiagramção pois ele é de uma apostila eu preciso dos outros textos para enviar para a [...].

Obrigado

Professor A
\end{abstract}

Percebemos que a posição do enunciador revela uma discordância da proposta feita, a qual pode ser comprovada com a sua solicitação de que não aconteça reescrita em seu texto por parte da equipe. O locutor justifica esse pedido, expondo como define a atividade de revisão de textos e o que espera dela:"mas a revisao é da parte linguistica $e$ vocÊs podem e devem fazer sugestão como colocaram no item 1, mas não podem reescrever o texto, podem reescrever como sugestão" (Professor A).

Sabemos que o enunciado, na perspectiva bakhtiniana de linguagem, não só recupera os já-ditos como antecipa dizeres possíveis. Assim, podemos notar uma afinidade da afirmação: "mas a revisao é da parte lingüística” (Professor A) com os já-ditos que concordam com o fato de que a "parte linguística" de um texto está ligada aos seus aspectos estruturais e ortográficos, o que não abarca, por exemplo, a sua reescrita, ainda que o motivo para a proposição dessas alterações, conforme expôs o Núcleo em seu $e$-mail anterior, tenha sido contribuir com o "fechamento do texto" e, em consequência, auxiliar na leitura do destinatário final, isto é, o aluno da EaD/FURG.

A continuação desse diálogo veio do Núcleo:

\begin{abstract}
[Professor A],
a idéia foi justamente reescrever a conclusão como sugestão, tanto que pedimos para que [...] olhasse. Acreditamos que qualquer texto precisa estar claro para qualquer leitor, independente da área de atuação, e é nesse sentido que trabalhamos, apoiados pela [uma autoridade do Núcleo] e por toda a equipe da SEaD. A maioria dos professores não se incomoda, mas fica a seu critério aceitar ou não, de modo que podemos restringir nossas intervenções em seus textos, sem problemas. [...] chegou a ver como ficou o final do texto? Não acha que ficou mais claro? Ou prefere que permaneça a versão anterior?

Um abraço e sempre à disposição,

\section{Equipe de Revisão Linguística}

Os enunciados acima evidenciam a elaboração de contrapalavras por parte do grupo de profissionais que atuam na equipe de revisão da $\mathrm{SEaD}$ em resposta às colocações do Professor A. Os dois primeiros trechos mostram um confronto direto com os dizeres do 
Professor A, conforme podemos confirmar: "a idéia foi justamente reescrever a conclusão como sugestão, tanto que pedimos para que [...] olhasse" e "Acreditamos que qualquer texto precisa estar claro para qualquer leitor, independente da área de atuação, e é nesse sentido que trabalhamos, apoiados [...] por toda a equipe da SEaD" (Núcleo de Revisão Linguística).

O primeiro deles dialoga com a afirmação colocada no e-mail do Professor A de que a reescrita realizada em seu texto não era uma sugestão, ainda que o tivessem avisado por e-mail a respeito desta intervenção. Já o segundo refuta a explicação dada pelo professor para a supressão de um período do seu texto, bem como para a troca na ordem de alguns fragmentos: "até porque o campo teórico provavelmente é diferente” (Professor A), o que vai de encontro à opinião do Núcleo, uma vez que para este: “... qualquer texto precisa estar claro para qualquer leitor, independente da área de atuação”. Como podemos observar, há novamente a ocorrência de uma tensão entre as opiniões dos dois atores do trabalho (um docente e o núcleo de revisores) que têm pontos de vistas distintos para a mesma atividade.

Os demais trechos da equipe de revisores estão centrados em explicitar ao professor, primeiramente, que a relação que se estabeleceu entre eles, nas correspondências trocadas, é atípica para o coletivo de trabalho, já que "A maioria dos professores não se incomoda [com a forma de trabalho da equipe de revisão]". Em segundo lugar, os argumentos expostos no e-mail em questão visam retomar o posicionamento da equipe de que a palavra final quanto ao material produzido é sempre do autor do texto: "mas fica a seu critério aceitar ou não, de modo que podemos restringir nossas intervenções em seus textos, sem problemas[...]” (Núcleo de Revisão Linguística). Ao retornar essa afirmação, o grupo de revisores parece estar buscando um modo de resolver a tensão criada, já que, conforme ratifica, o Professor é o detentor da palavra final na elaboração do texto, o que significa que ele pode decidir livremente o que acha relevante ou não para a constituição final de seu material.

Por outro lado, a equipe não deixa de salientar o seu posicionamento sobre as alterações realizadas, uma vez que, afora as considerações tecidas, o Núcleo retoma também o argumento já colocado no segundo e-mail encaminhado para o Professor A, o qual se constrói pelo destaque ao posicionamento da equipe de que as intervenções realizadas no texto tiveram por intuito deixar a produção textual mais clara ao leitor: "[...] chegou a ver como ficou o final do texto? Não acha que ficou mais claro?” (Núcleo de Revisão Linguística). Como vemos, para o Núcleo, o que justifica a pertinência da sua proposta de reescrita de trechos é ter como objetivo de trabalho auxiliar na leitura e consequente compreensão do material que subsidiará a formação do leitor final, o aluno da EaD/FURG.

Segundo Bakhtin; Volochínov (1999), o uso da linguagem é inseparável dos conteúdos ideológicos. Recuperar tal postulado nos é fundamental, pois, ao buscarmos compreender de que modo as relações se estabelecem no desenvolvimento das atividades do Núcleo, vemos que os pontos de vista dos sujeitos sempre embasam as suas interações e, em consequência, a construção da linguagem, o que pode ocasionar concordância ou conflito, a depender da situação em que se encontram.

No diálogo até agora exposto, observamos, por exemplo, que ambos os interlocutores expõem as suas interpretações para a situação que se estabeleceu, bem como acreditam que estão agindo da melhor maneira possível no desenvolver de suas atividades, seja de professor ou de revisor. Logo, é no imbricamento destas duas funções que modos distintos de visualizar o seu papel e a atividade do outro emergem e originam situações de conflito, tais como as que vimos analisando. 
Esta atitude do Núcleo demonstra também o fato de que a atividade é repensada pelo ator do trabalho, o que, na opinião dos analistas da atividade (CLOT, 2001), é fundamental que ocorra quando se pretende aprimorar o trabalho realizado. Na verdade, a análise da atividade mostra que renormalizar, isto é, alterar a norma, mesmo seguindo o que ela prescreve, é a maneira mais comum de realizar qualquer atividade. Afinal, a atividade nunca é realizada exatamente como é prescrita, uma vez que, em sua prática, vários fatores se interpõem em sua alteração.

Destaca-se aqui o modo como o Núcleo lida com os textos dos professores, que muito se assemelha à técnica da construção de feedbacks defendida por Soares (2009), já que, segundo a autora, os feedbacks devem ter por função principal auxiliar o autor do texto na sua reescrita, ao evidenciar o posicionamento de um leitor interessado com a escrita alheia, ao invés de um mero examinador (no caso do professor). Ora, pudemos verificar, no diálogo e trechos analisados, que o Núcleo trabalha exatamente a partir da construção de feedbacks, os quais inclusive estão no foco da interação entre a mencionada equipe e o Professor A.

Vemos ainda um reforço na assertiva do Núcleo de que o modo como se estabeleceu a interação entre ele e o Professor A é incomum: "Conforme lhe dissemos, salvas raríssimas exceções, os professores entendem que a função da equipe de produção de material, da qual fazemos parte, é cooperar e contribuir com a elaboração do material, sendo que, por conta disso, somos corresponsáveis pela versão recebida pelo aluno. Ao reforçar para o docente que a visão que este tem quanto à atividade de revisão realizada em seu texto é uma exceção, bem como ao se colocar enquanto corresponsável pelo material que chega ao discente, o Núcleo de Revisão explicita que partilha de um modo de dizer que é distinto do compreendido pelo Professor A, pois a equipe se visualiza como coautora do processo e não como executora de ajustes gramaticais apenas.

Logo, vê-se que a construção de um trabalho colaborativo é um dos pontos defendidos e praticados pelo Núcleo, que diverge do professor na definição de sua atividade como "a revisão linguística" a partir de um viés discursivo da linguagem. Admitir esta postura lhes possibilita, inclusive, a alteração de um dado trecho do texto, ou seja, fazer "contribuições semânticas" (ou textuais) quando, na opinião do Núcleo, tal mudança tiver por finalidade auxiliar na clareza da produção textual.

\section{Considerações finais}

O estudo realizado nos permitiu mostrar que o trabalho desenvolvido pela equipe de revisão não acontece de modo isolado, solitário, individual, e tampouco lida apenas com a materialidade textual per se, isto é, sem considerar o aspecto discursivo dos textos, o contexto de sua inserção, o leitor a quem se destina e as relações que devem ser estabelecidas com os autores das produções revisadas. $O$ entendimento da linguagem de modo dialógico-discursivo nos permitiu olhar para as situações enunciativas, para os textos analisados e para a rede de interlocução envolvida de modo amplo, visando ir além da constatação quantitativa dos elementos gramaticais e/ou estritamente linguísticos que perpassam os diálogos estabelecidos. Examinamos, assim, a rede de interlocução envolvida no processo, as diferenças de valoração, os conflitos e acordos voltados para um objetivo unificador comum.

Nossa filiação teórica, que foi escolhida a partir das características do objeto, uma vez que não iniciamos com categorias prévias nas quais buscamos enquadrar o objeto, oportunizou-nos também buscar melhor compreender o estatuto do ator do trabalho a partir das situações em ele está inserido, bem como tentar entender a natureza das relações 
dialógicas estabelecidas com os professores e dar voz ao revisor para que ele expusesse como visualiza a si mesmo e ao seu métier no processo do qual faz parte ativa. Como pudemos demonstrar, o trabalho é um movimento de dupla antecipação (SCHWARTZ, 2002) entre um saber conceitual e outro saber adquirido na situação concreta de desenvolvimento da atividade, cabendo ao analista considerar cada uma dessas antecipações como constitutivas do fazer analisado e a perceber que o não-concretizado faz parte da atividade tanto quanto o faz o efetivamente realizado.

Verificamos, quanto à atividade pesquisada, que os atos enunciativos dos docentes no contato com o Núcleo, e a reflexão dos revisores sobre sua própria atividade comprovaram que o fazer colaborativo é constitutivo da atividade da equipe de revisão, evidenciando-se aí a construção, por vezes tensa e conflituosa, de diálogos, bem como a presença e o contato entre diferentes posicionamentos dos atores do trabalho e dos demais envolvidos com a atividade a respeito desta, voltados para o fim comum da produção de um texto adequado aos usuários finais. Em vista disso, ratificamos que pudemos comprovar que é justamente a existência desses diálogos que mostram as negociações necessárias para o resultado final, e, assim, permitem a caracterização desse trabalho como um agir conjunto cooperativo e colaborativo, sem que isso apague, insistimos, as tensões, constitutivas e/ou casuais, que aparecem no decorrer da atividade.

Uma contribuição adicional da pesquisa aqui examinada foi o uso de procedimentos teórica e praticamente válidos do ponto de vista do objeto examinado, e não uma imposição das teorias ou de metodologias ao objeto. Tratou-se assim de uma pesquisa qualitativa que não partiu de categorias prévias, mas de princípios teóricos da teoria dialógica, de estudos ergológicos e ergonômicos e das propostas dialógico-interativas da Clínica da Atividade, princípios esses que, em diálogo permanente entre si e com os dados, fizeram-nos chegar a categorias e processos de análise do ponto de vista da descrição da atividade em seus vários aspectos: o objeto e suas nuanças foram o determinante da metodologia.

Devemos destacar ainda que optamos por trabalhar com as vozes dos atores do trabalho envolvidos diretamente com a atividade pesquisada (professores e revisores) no intuito de verificar também de que modo esses profissionais compreendem a atividade realizada e os papéis que nesta ocupam de sua própria perspectiva laboral, o que foi vital para complementar a análise do material textual-discursivo. Dar voz aos atores criou um espaço de pesquisa no qual os sujeitos estudados não foram apenas objetos de estudo, mas igualmente sujeitos em diálogo com a pesquisa e a pesquisadora, permitindo assim o entendimento da rede de interlocução que constitui o contexto e a forma específica de estruturação da atividade, o lócus em que essa atividade adquire sentido.

\section{REFERÊNCIAS}

BAKHTIN, M.; VOLOCHINOV, V. N. Marxismo e Filosofia da Linguagem: problemas fundamentais do método sociológico na ciência da linguagem. Tradução Michel Lahud e Yara Frateschi Vieira. 14. ed. São Paulo: Hucitec, 2010.

BARBOSA, V. Uma análise dialógica da atividade de revisão linguística em EaD. Dissertação (Mestrado em Linguística Aplicada) - Universidade Católica de Pelotas, Pelotas, 2012.

BRASIL. Ministério da Educação. Orientações e diretrizes para o pagamento de bolsas no âmbito do Sistema Universidade Aberta do Brasil (UAB). Brasília: MEC, 2009. 
CLOT, Y. A função psicológica do trabalho. Trad. A. Sobral. Petrópolis, RJ: Vozes, 2006.

CLOT, Y. Clínica do trabalho, clínica do real. Tradução indicativa de Adail Sobral. Le journal des psychologues, n.185, p.1-9, 2001. Disponível em: http://www.pqv.unifesp.br/ clotClindotrab-tradkslb.pdf. Acesso em: abr. de 2011.

CLOT, Y., FAÏTA, D., FERNANDEZ, G.; SCHELLER, L. Entretiens en autoconfrontation croisée: une méthode en clinique de l'activité. Tradução indicativa de Adail Sobral. Éducation Permanente: Clinique de l'activité et pouvoir d'agir, n. 146, p.1726, 2001.

CLOT, Y.; FAÏTA, D. Genres et styles en analyse du travail: concepts et méthodes. Tradução indicativa de Adail Sobral. Travailler, n. 4, Revigny-sur-Ornair, Fr: Martin Media, p. 7-42, 2000.

FUNDAÇÃO UNIVERSIDADE FEDERAL DO RIO GRANDE. CONSELHO UNIVERSITÁRIO. Resolução, n. 034, de 24 de abril de 2007. Disponível em: $<$ http://www.conselho.furg.br/converte.php?arquivo=delibera/consun/03407.htm>. Acesso em: 12 jan. 2007.

NOUROUDINE, A. A linguagem: dispositivo revelador da complexidade do trabalho. In: FAITA, D. ;SILVA, M. Souza e (Org.). Linguagem e trabalho: construção de objetos de análise no Brasil e na França. Tradução Ines Polegatto e Décio Rocha. São Paulo: Cortez, 2002. p.17-30.

NOVELLO, T. Cooperar no enatuar de professores e tutores. 163 f. 2011. Tese (Doutorado em Educação Ambiental) - Universidade Federal do Rio Grande. Fundação Universidade do Rio Grande, Rio Grande, 2011.

OLIVEIRA, R. R. F. Revisão de textos: da prática à teoria. Natal: Edufrn, 2010.

SCHWARTZ, Y. A linguagem em trabalho. In: SCHWARTZ, Y.; DURRIVE, Y. (Org.). Trabalho \& Ergologia: conversas sobre a atividade humana. Tradução Milton Athayde e Jussara Brito et al. Niterói: UFF, 2007, p. 131-188.

SILVA, M. C. e Souza. O ensino como trabalho. In: MACHADO, A. R. O ensino como trabalho: uma abordagem discursiva. Londrina: EDUEL, 2004, p. 81-104.

SOARES, D. Produção e revisão textual: um guia para professores de Português e de Línguas Estrangeiras. Petrópolis: Vozes, 2009.

SOBRAL, A. Dizer o "mesmo" a outros: ensaios sobre tradução. São Paulo: Special Book Services, 2008.

SOBRAL, A. Do dialogismo ao gênero: as bases do pensamento do Círculo de Bakhtin. São Paulo: Mercado das Letras, 2009.

TAYLOR, Frederick Winslow. Os Princípios da Gestão Científica. Lisboa: Silabo, 2011.

UNIVERSIDADE Aberta. Furg. Informações para a produção de material: produção de material. Disponível em <http://www.uab.furg.br//file.php/1/guiadosprofessores/html/ fluxograma.html>. Acesso em: 17 fev. 2012

Recebido em fevereiro de 2013.

Aprovado em abril de 2013. 